Pedagogía y Saberes n. ${ }^{\circ} 56$

Universidad Pedagógica Nacional

Facultad de Educación. 2022. pp. 69-82

\title{
Resignificación del trabajo y la práctica docente en educación superior a la luz de la crisis por el virus SARS-CoV-2
}

Resignification of the Work and Teaching Practice in Higher Education in the Light of the Crisis Caused by the SARS-CoV-2 Virus Ressignificação do trabalho e da prática docente no ensino superior frente à crise provocada pelo vírus SARS-CoV-2

María de los Ángeles Castillo Flores* Claudia Sernas Hernández** Jacobo González Baños***

\section{Para citar este artículo}

Castillo, M., Sernas, C. y González, J. (2022). Resignificación del trabajo y la práctica docente en educación superior a la luz de la crisis por el virus SARS-CoV-2. Pedagogía y Saberes, (56). https://doi.org/10.17227/pys.num56-13108

* Doctora en Sociología, Universidad Nacional Autónoma de México. Docente investigadora, Universidad Pedagógica Nacional, Ajusco, Ciudad de México. Miembro del cuerpo académico Autonomía Universitaria. Correo: mcastillo@upn. mx. Orcid: https://orcid.org/0000-0002-6482-4469.

** Magíster en Desarrollo y Planeación de la Educación, Universidad Autónoma Metropolitana-Xochimilco. Docente investigadora, Universidad Pedagógica Nacional, Ajusco, Ciudad de México. Miembro del cuerpo académico Autonomía Universitaria. Correo: claudiasernas@hotmail.com. Orcid: https://orcid.org/0000-0002-1317-8807.

*** Doctor en Sociología, Universidad Nacional Autónoma de México. Profesor, Universidad Pedagógica Nacional-Ajusco, Ciudad de México. Miembro del cuerpo académico Autonomía Universitaria. Correo: jagonzalez25@hotmail.com. Orcid: https://orcid.org/0000-0003-2050-3492. 


\title{
Resumen
}

Este artículo de reflexión es el resultado del proyecto de investigación del cuerpo académico de la Universidad Pedagógica Nacional (UPN)-Ajusco, México, titulado "Trabajo y práctica docente en educación superior. Narrativas y relatos desde los actores en época de pandemia". De esta forma, nos dimos a la tarea de analizar cómo habíamos enfrentado, transformado y modificado nuestro trabajo y práctica docente en un contexto de pandemia por el virus sars-cov-2, y damos cuenta de ello a través de nuestra experiencia. Así pues, utilizamos la narrativa como andamiaje metodológico y reflexivo y los conceptos teóricos de Freire para comprender los elementos comunes que enfrentábamos y llegamos a la conclusión de que la educación debe ser instrumento liberalizador, así como de construcción de la autonomía. Con este fin, reorganizamos nuestro trabajo y práctica docente a partir de la construcción de una relación dialógica, en donde reconocemos y nos reconocemos como sujetos activos, que se deben modificar o transformar de manera permanente, no en función del mercado sino de las necesidades de quienes participan en el proceso de enseñanza-aprendizaje y, a partir de esto, elaboramos una propuesta de un programa único que adaptamos a diferentes asignaturas. Modificamos la práctica bancaria por una docencia reflexiva, en donde construimos de manera conjunta objetivos y fines de las asignaturas. Desde el trabajo cotidiano reconstruimos y con el uso de las tecnologías desestructuramos la clase tradicional y presencial, hacia una interacción distinta y dialógica con los alumnos, lo que resignificó nuestra labor docente.

\section{Palabras clave}

trabajo docente; práctica docente; resignificación; autonomía; narrativas

\begin{abstract}
This reflection article is the result of the research project "Work and teaching practice in higher education. Narratives and stories from the actors in pandemic times". This text was created by a group of professors from the Universidad Pedagógica Nacional (UPN)Ajusco, Mexico. We undertook the task of analyzing and accounting for how we had faced, transformed and modified our work and teaching practice in the context of the sars-cov-2 virus pandemic. We use the narrative as the methodological and reflective scaffolding and Freire's theoretical concepts to understand the common elements faced during this process. We also concluded that education should be a liberalizing instrument, as well as an autonomy builder. In the meantime, we reorganized our work and teaching practice based on the construction of a dialogic relationship, where we recognized ourselves as active subjects, who must be permanently modifying or transforming, themselves not depending on the market but on the needs of those who participate in the process of teaching and learning. With these bases, we elaborate a proposal for a unique program that adapts to different subjects. We modify the banking practice changes for a reflective teaching practice, where we jointly construct the objectives and the purposes of the courses. From our daily work, and with the use of technologies, we deconstructed the traditional and face-toface class and built an interaction with the students in a different and dialogical way. Basically, we re-signified our teaching work.
\end{abstract}

\section{Keywords}

teaching work; teaching practice; resignification; autonomy; narratives

\section{Resumo}

Este artigo de reflexão é resultado do projeto de pesquisa do corpo acadêmico da Universidade Nacional Pedagógica (UPN)-Ajusco, México, intitulado "Trabalho e prática docente na educação superior. Narrativas e histórias desde os atores em tempos de pandemia". Desta forma, assumimos a tarefa de analisar e contabilizar, por meio de nossa experiência, como havíamos enfrentado, transformado e modificado nosso trabalho e prática docente em um contexto de pandemia pelo vírus sars-cov-2. Assim,utilizamos a narrativa como arcabouço metodológico e reflexivo, junto com os conceitos teóricos freireanos, para compreender os elementos comuns que enfrentamos, chegando à conclusão de que a educação deve ser um instrumento de liberalização, bem como de construção da autonomia.Para isso, reorganizamos nosso trabalho e a prática docente a partir da construção de uma relação dialógica, onde nos reconhecemos e nos reconhecemos como sujeitos ativos, que devem-se modificar ou transformar permanentemente, não só a partir do mercado, mas das necessidades de quem participa do processo de ensino aprendizagem e, com base nisso, elaboramos uma proposta de programa único que adaptamos a diferentes disciplinas. Modificamos a prática bancária para uma prática pedagógica reflexiva, onde construímos em conjunto os objetivos e finalidades das disciplinas. A partir do nosso trabalho diário reconstruímos e com o uso de tecnologias desconstruímos a aula tradicional e presencial, em direção a uma interação com os alunos de uma forma diferenciada e dialógica, o que ressignificou o nosso trabalho docente.

\section{Palavras-chave}




\section{Introducción}

Como docentes de la Licenciatura de Sociología de la Educación en la Universidad Pedagógica Nacional -Ajusco ubicada en la capital de la República Mexicana, hemos sentido y visto cómo se ha ido transformando tanto nuestro trabajo como nuestra práctica docente en los últimos años como resultado no solo de las revoluciones científico-tecnológicas (tercera, cuarta y recientemente quinta) que continuamente exigen a la educación superior modificaciones en la estructura curricular y en la actualización del contenido de las materias, sino también debido a los cambios internos propios del sistema educativo nacional y sus continuas reformas educativas en los distintos niveles.

\section{Partimos de que la educación}

es permanente en razón, por un lado, de la finitud del ser humano y, por otro, de la conciencia que éste tiene de su finitud [...] su naturaleza la noción de no sólo saber que vivía, sino saber que sabía y así saber que podía saber más [...] no es posible ser un ser humano sin hallarse implicado de alguna manera en alguna práctica educativa [...] el ser humano jamás deja de educarse... (Freire, 2011, pp. 23-24)

La importancia del cambio permanente en la educación no es un problema de las políticas y reformas educativas, sino que es parte inherente al desarrollo humano, de su interés en su entorno tanto en la sociedad como en la naturaleza. Estos elementos son los que hacen que se busque un cambio constante; de aquí su importancia en cualquier nivel educativo. De igual manera consideramos que ante el cambio generado por el virus SARS-CoV-2 -2 es necesario tomar en cuenta que hoy más que nunca

aprender es construir, reconstruir, comprobar para cambiar, lo que no se hace sin apertura al riesgo y a la aventura del espíritu. A esta altura, creo poder afirmar que toda práctica educativa demanda sujetos, uno que, al enseñar, aprende, otro que, al aprender, enseña, de allí su aspecto gnoseológico; la existencia de objetos, contenidos para hacer enseñados y aprendidos, incluye el uso de métodos, de técnicas, de materiales; implica a causa de su carácter directivo, objetivo, sueños, utopías, ideales. De allí su politicidad cualidad que tienen [sic] la práctica educativa de ser política de no poder ser neutral. (Freire, 2002, p. 68)

La práctica educativa tiene que ser producto de un proceso social y socioeducativo en el que educador y educando aprenden y enseñen juntos, en el cual ambos puedan visualizar e identificar los obstáculos para llevar a cabo una transformación de esa realidad.

\section{Las narrativas como elemento de construcción del sujeto}

La reflexión como docentes de educación superior ha sido un proceso significativo que ha construido subjetividades. Ante una práctica escolar regida por una educación bancaria vertical, un grupo de profesores reorientamos y reconstruimos nuestro trabajo y práctica docente, con el fin de plantear una educación dialógica en donde se construyan saberes y nuevas formas de conocimiento. En este sentido, la documentación narrativa fue un elemento que nos permitió dialogar e indagar aquellos acontecimientos que nos habían construido como sujetos objetivados, pero también el reconocimiento y la interpretación de nuevos constructos derivados de la reflexión, ya que como lo plantea Bolívar (2002), la narrativa no solo es una metodología, sino la construcción del sujeto mediante la propia experiencia y se configura como construcción social de la realidad.

La narrativa de nuestro trabajo como docentes en esta coyuntura de pandemia nos permitió la interacción entre el investigador y el investigado más allá de la perspectiva del sujeto sujetado (Imaz, 2011), entrecruzamos reflexiones, compartimos nuestras prácticas docentes, pusimos en el centro discusiones y diálogos comunes producto de nuestro trabajo. La experiencia de reflexionar a través de nuestra propia voz a partir de las narrativas convertidas en textos nos dio la posibilidad de revaluar el contexto educativo, de mirarnos con una nueva visión, como señala Ferrarotti: "saber escuchar y en esta capacidad de escucha, saber realzar la búsqueda, renunciar a la cultura entendida como capital privado e instrumento antagónico de confrontación y de poder [...] lo singular reapropiado del universal e histórico" (2011, p. 97). Esto es, nos propusimos vincular el texto producido por el investigador en la coyuntura específica de pandemia por el coronavirus, en espacios escolares virtuales y reflexionamos y comprendimos que este es un proceso que nos dio ejes de análisis como cuerpo académico de profesores, de investigadores para hacer propuestas concretas en nuestra práctica docente. "Entender la vida social vivida, tanto por el investigador como por él o los sujetos de estudio [...] incorporar la visión de los propios sujetos sociales" (Imaz, 2011, p. 44) y a partir de ello reconstruir nuestra propia práctica.

Es importante mencionar que las narraciones que derivaron en los espacios de trabajo colaborativo se orientaron a desarrollar y poner a prueba nuevas formas de trabajo a partir de lo que sucedía en los espacios escolares virtuales y con los actores educativos que estábamos en un lugar y tiempo definidos. 
Describimos, explicamos, platicamos y recreamos nuevas interpretaciones críticas sobre nuestro quehacer educativo y apostamos por una nueva forma de organizar nuestro trabajo, pero sobretodo reconocimos que teníamos que reconstruir los procesos de enseñanza-aprendizaje con los estudiantes dado que es un nuevo contexto, la educación virtual. Esto se muestra en la siguiente narrativa de la profesora B:

Una de las grandes reflexiones que realizamos como sujetos en nuestra vida cotidiana académica, emergió de una plática casual entre compañeros de allí, surgió la necesidad de una transformación de nuestro quehacer educativo. Teníamos alumnos nuevos con nuevos constructos ideológicos y lo que necesitábamos era comprenderlos y construirlos de una forma distinta a como lo estaban planteado el sistema capitalista global ${ }^{1}$. (Profesora B)

En esta nueva reorientación de nuestra labor educativa, retomamos las propias construcciones que los estudiantes han edificado. La narración de nuestras propias experiencias dio cuenta de "que como sujetos traemos consigo conocimientos socialmente construidos en la práctica comunitaria" (Freire, 2002, p. 31) y que, en una nueva relación educativa, la tomamos como parteaguas para trabajar esos saberes con los contenidos académicos. El proceso fue complicado, ya que los estudiantes han reproducido pautas escolares muy conductistas, lo que no facilitó nuestro trabajo; sin embargo, se fueron dando frutos en un tiempo determinado, como lo establecemos en el siguiente relato:

Trabajé con ellos desde la construcción de sus propias narrativas y traté de que sus saberes empíricos [sic] relacionarán conceptualmente con los contenidos de la materia de Economía Mexicana. No fue fácil, pero después, ellos se dieron cuenta que ya traían saberes de esta área del conocimiento, pero que nunca habían relacionado la parte teórica con lo que vivían día a día. (Profesora A)

Así, desde las narrativas contamos parte de nuestras experiencias profesionales y personales. Relatando lo que nos pasaba en un nuevo contexto, comprendimos a través de nuestras propias voces las transformaciones necesarias, y a partir de ello le dimos un nuevo significado a nuestro trabajo, por cuanto nos mostraron los distintos aspectos que observamos entre nosotros como sujetos dentro de un tiempo y espacio determinados, a través de reconocernos como sujetos inmersos dentro de la estructura educativa, lo que nos ayudó a comprender, a reflexionar y dar cuenta de aquellos sucesos

1 En todas las citas de las narrativas de los profesores se mantiene la escritura del texto original. subjetivos que construimos e interiorizamos como parte de nuestro trabajo como docentes, para después objetivarlos en una práctica reflexiva.

\section{La Universidad Pedagógica Nacional: ¿un espacio de reflexión?}

La Universidad Pedagógica Nacional - Ajusco es una institución creada para la actualización y profesionalización del docente que atendía a la educación básica (primaria y secundaria) en México. Por decreto presidencial del 29 de agosto de 1978, se crea la Universidad Pedagógica Nacional - Ajusco como un organismo desconcentrado de la Secretaría de Educación Pública, el Ministerio de Educación en México $^{2}$. En el decreto de creación, se sanciona el marco de legalidad y operación de la Universidad.

Destaca de ello la característica de ser orgánicamente desconcentrada, lo que significa que pertenece a las estructuras de gobierno de la Secretaría de Educación Pública, donde se toman las decisiones importantes sobre su crecimiento y desarrollo; por ejemplo, la creación de campus e instalaciones y la elección del rector son funciones dependientes de la Secretaría de Educación Pública. Según el organigrama, la universidad es nacional y tiene representaciones llamadas unidades en todos los estados de la República. Estas pueden tener subsedes, según las necesidades de las regiones. En el original del decreto de creación, la Unidad Ajusco, ubicada en la Ciudad de México, se constituyó en la sede central de toda la universidad. Se ubican allí las autoridades: Rectoría, Secretaría Académica, Secretaría Administrativa y Abogado General.

Cabe resaltar que la situación de la institución se empezó a deteriorar en los años noventa del siglo anterior como resultado de las políticas neoliberales (restricción presupuestaria y reorganización administrativa).

\section{La construcción de un cuerpo académico}

El cuerpo académico Autonomía Universitaria y Educativa es una organización de profesores, que surgió a partir de la incorporación de la Universidad a una

2 Según la ley mexicana, los decretos presidenciales se encuentran en una jerarquía menor respecto de otras formas de legislación, tal como una ley orgánica. Esta debe de ser sancionada por el Congreso General Nacional (tanto por la Cámara de Diputados como la de Senadores). 
nueva propuesta de estructura académica que se había generalizado para la educación superior, con la finalidad de promover y desarrollar las actividades de docencia, investigación, tutoría y gestión académica. En la Universidad se acordó su conformación de acuerdo a líneas de investigación y generación de conocimientos; estas a su vez se concentraron en cinco áreas que las agrupan; nosotros pertenecemos al Área 1. Política Educativa Procesos Institucionales y Gestión.

La creación de los cuerpos académicos es la expresión de la vida académica y de la necesidad de interacción, de agrupamiento para la producción de conocimientos y de la organización del trabajo de sus integrantes de manera colectiva e individual. Desde una perspectiva crítica, se puede decir que estos son la expresión de una autonomía de base, de resolución de problemas concretos, de expresividad sin fronteras de una formación y actividad profesional, de una libertad comprometida con el paradigma científico social. Desde el punto de vista institucional, es la nueva forma de gestión de organización del personal docente, como lo establecemos en el siguiente relato:

la creación de los cuerpos académicos en la Universidad Pedagógica se dio a partir de una necesidad de trabajo colaborativo. Bajo Líneas de generación y aplicación del conocimiento nos agrupamos para construir saberes desde una perspectiva crítica, sobre la realidad socioeducativa del país. (Integrante del cuerpo académico Autonomía Universitaria y Educativa)

En el caso del cuerpo académico Autonomía Universitaria y Educativa nos hemos dedicado al análisis de problemáticas derivadas del capitalismo implementado en México y de las decisiones de política educativa que han repercutido en el sistema educativo nacional.

\section{La experiencia del cuerpo académico en la pandemia: resignificación del trabajo y la práctica docente}

Uno de los elementos primordiales que dejó ver la pandemia en la educación pública de México fue la dificultad de los estudiantes universitarios para utilizar las tecnologías y sus escasas habilidades y conocimientos en el manejo de plataformas digitales educativas, ya que el empleo de las redes sociales y la navegación en internet de los alumnos de educación superior no fueron garantía del uso de las herramientas tecnológicas que se necesitaban para implementar una educación virtual de emergencia.
En el caso de la Universidad Pedagógica Nacional, y desde la visión de las autoridades, en esta nueva educación, de lo único que se trataba era de seguir las mismas rutinas en el proceso de enseñanza-aprendizaje, lo cual establecía: dar clase con los mismos procedimientos didácticos y enseñar contenidos con las mismas formas tradicionales, es decir, cumplir con los programas de estudio y entregar las evaluaciones puntualmente, sin considerar la nueva situación de profesores y alumnos.

En el uso de herramientas tecnológicas, nos enfrentamos a nuestro poco conocimiento en el manejo, pero logramos adaptarnos y construir estrategias de aprendizaje, pero, sobre todo aprendimos a trabajar colaborativamente, como lo establecemos en el siguiente párrafo:

En el inicio de la pandemia, cuando se dio el confinamiento empezamos por buscar formas para comunicarnos, algunos de nosotros empezamos a utilizar Zoom con los estudiantes. La generalización del uso de esta plataforma para las clases nos abrió la posibilidad de la comunicación visual, los problemas que enfrentamos para su uso fueron iguales que las de los alumnos, falta de banda ancha de Internet, de computadoras adecuadas y del manejo de las plataformas. Fue notorio que la edad es un factor que define el uso y manejo de la tecnología, somos un cuerpo académico conformado por profesores de distintas edades, la profesora "B" es la de menor edad y la que se mueve con mayor facilidad en este terreno, ella ha sido la que brinda asesoría y busca solucionar los problemas en esta área. (Cuerpo académico Autonomía Universitaria y Educativa)

En este sentido, en el cuerpo académico utilizamos las plataformas digitales para generar espacios de cooperación, ensayo y reflexión, los alumnos iniciaron con la narrativa sobre el impacto de la pandemia en su vida cotidiana y, de manera particular, en su vida académica, trabajaron en equipo las narrativas, y de los elementos detectados en el grupo se establecieron líneas de discusión y se adaptó la parte teórica de cada materia a las nuevas necesidades, lo que nos permitió relacionarnos de una forma más cercana, reconocer nuestros conocimientos y establecer sesiones de discusión que dieron pie a un trabajo más reflexivo, según las narrativas del cuerpo académico.

Las reuniones a través de Zoom abrieron la posibilidad de continuar nuestro trabajo. Las primeras discusiones fueron sobre la crisis económica y política producto de la pandemia. Ubicamos que esta crisis fue producto de la privatización de los servicios de salud y de la reducción del Producto Interno Bruto en México en los servicios sociales en general, en un segundo momento nos vimos en la necesidad 
de discutir de manera continua lo que estaba sucediendo en los cursos, problemas de los estudiantes y dificultades que todos estábamos enfrentando, estos temas los comentamos retomando siempre el contexto general nacional e internacional. (Cuerpo académico Autonomía Universitaria y Educativa)

En cuanto a los alumnos, reconstruimos con ellos el trabajo cotidiano, y el uso de las tecnologías desestructuró la clase tradicional-presencial. Esto generó una interacción distinta entre los profesores con los alumnos, lo cual nos llevó a reconstruirnos y a tratar de identificarnos con los estudiantes no solo como sujetos, en cuanto unión de subjetividades y conocimientos, sino con la mirada de un "nosotros".

Nuestra labor educativa se transformó desde lo que Freire (1998) plantea como una posición ética, de compromiso, en donde el profesor construye nuevos saberes tales como: la seguridad, el compromiso, la comprensión, el saber escuchar a los alumnos, la empatía y flexibilidad en un contexto de miedo. Los siguientes relatos dan cuenta de ello:

Los docentes tendríamos que convertirnos (no en psicólogos, no en trabajadores sociales, no en capataces) sino ser un apoyo fundamental, para informar a los alumnos sobre qué es el virus, desde la biología, en el caso de primaria, la matemática, la física con los de secundaria, la estadística en el caso de las universidades... es decir usar lo que nos da el contexto y cómo lo incorporas a ese proceso de enseñanza. (Profesor A)

Es importante que los docentes seamos empáticos, que cuando iniciemos la clase le demos importancia a lo que está sucediendo en su contexto. Establecer una relación cordial, desde un hola buenos días, cómo están, cómo está su familia, cómo va la zona donde viven. Esto nos ayuda a identificar su contexto situacional y a realizar un diagnóstico personal de cómo están nuestros estudiantes, mostrar preocupación por ellos y ofrecer acompañamiento durante las clases virtuales. (Profesor c)

Es decir, se debe transformar desde la reflexión de la práctica docente. De acuerdo con Velasco, "en la tradición fenomenológica se asume que el lenguaje tiene una función constitutiva de mundos, que vincula la existencia de fenómenos, cosas o acontecimientos [...] el lenguaje expresa las características del mundo histórico en que se vive" (2012, p. 203). Con las narrativas, se demanda la reflexión desde la codificación del texto y las formas de enseñanza en diversos escenarios. Uno de sus aspectos más importantes que se deben tomar en consideración son los emocionales, pensando que el proceso de enseñanza-aprendizaje significa el reconocimiento de los sujetos y la transformación de los mismos en un proceso dialógico que considera el contexto en el que se lleva acabo.

Nuestra transformación se dio desde diferentes aristas: el trabajo docente desde la totalidad, el trabajo y la práctica docente, el uso de las tecnologías y, finalmente, desde la posición empática con los sujetos en la construcción dialógica de los saberes.

\section{El trabajo docente desde la totalidad}

Cuando decidimos abordar los fenómenos educativos y sociales que estaban trastocando nuestro trabajo como docentes, ubicamos el método que entiende a la sociedad como una totalidad teniendo en cuenta nuestras formaciones profesionales (economistas, sociólogos, especialistas en educación, entre otras). Esto permitió entender que los fenómenos particulares y dispersos son trascendidos dialécticamente, esto es, son procesos sociales inmersos en continuas contradicciones. En la construcción de la totalidad, desde la generación del virus hasta los efectos nacionales y mundiales, tanto en lo económico como en lo social y particularmente en lo educativo, identificamos los elementos concretos de la realidad de los sujetos, y consideramos el proceso social y educativo como parte del desarrollo histórico. Estos elementos esenciales nos ayudaron a dar cuenta del transcurso de los acontecimientos emanados de la crisis por la pandemia por SARS-CoV-2. Este hecho, visto como fenómeno histórico, nos llevó a la autoconsciencia, para identificar y superar en el proceso en el que se desarrollan los sujetos, $y$, al regresar nuevamente al ámbito concreto, dio la posibilidad de transformar el fenómeno o situación concreta de la que se partió (Castillo, 2019). "La superación no debe interpretarse solamente en sentido negativo, destructivo, como liquidación. Es también 'superación' en sentido de mantenimiento, de conservación...” (Bloch, 1985, p. 12). Esto nos llevó a pensar no solo en la crítica sino también en plantear soluciones.

Para los alumnos ya no es viable estar en clase "virtual" [...] es un problema, porque los programas fueron diseñados para clases presenciales, se tiene una estructura diseñada para estar en el aula, tampoco pueden cumplirse las horas institucionales establecidas en esta nueva situación. (Profesora B)

El sistema tradicional es el sistema más eficaz para el aprendizaje, diría Piaget, pero no para la construcción. Existe una diferencia entre el sistema escolarizado y a distancia. En la plataforma Moodle, 
para educación a distancia se contabiliza el tiempo en la plataforma como una forma de fiscalización, la preparación de las clases a veces te lleva todo el día, tienes que prepararte para cuando los alumnos no cumplan con las tareas, y tienes que seguir de manera estricta el programa. No es en función del aprendizaje creativo. Se abren foros, chat con opiniones sin fundamento. Los alumnos no leen libros, sino mucho material de internet [...] creo que hay mucha diferencia. (Profesor c)

Se deben buscar mecanismos para flexibilizar las calificaciones, buscar alternativas para los alumnos como los cursos intermedios [...] no es lo mismo el docente frente a grupo que el docente frente a la computadora [...] como docentes no debemos aceptar las nuevas condiciones de trabajo. (Profesor D)

Una vez nos ubicamos en una realidad histórica concreta, nos dimos a la tarea de modificar nuestro trabajo docente. El punto de partida es el concepto de trabajo, el que Marx define como actividad genérica de mujeres y hombres para obtener los recursos materiales necesarios para su sobrevivencia con una actividad en el que objetiva y materializa su capacidad mental y energía física. Nosotros consideramos que el trabajo es un elemento que constituye y reconstituye a los sujetos y a la totalidad concreta conformada por las relaciones sociales que se expresan en la interacción de clases en la sociedad capitalista a través de conflictos e intereses distintos, tanto individuales como colectivos. Es un proceso en el que se suceden de manera continua cambios, producto tanto de la interacción de los sujetos, como en el interior de los sujetos mismos. El trabajo docente es una actividad que expresa el contexto social en donde se realiza; de manera particular en su cotidianidad y de forma general como manifestación del desarrollo de la sociedad que en ese momento se lleva a cabo como un proceso continuo que constituye el devenir de la sociedad capitalista (Castillo, 2019). Para los profesores del cuerpo académico Autonomía Universitaria y Educativa:

El contexto que nos tocó nos obligó a cambiar nuestra forma de trabajo. Había conflictos en la Universidad Pedagógica Nacional y después se vino la pandemia. La interacción con los alumnos se modificó. Se puede hablar de dos momentos, cuando nos confinaron, no sabíamos qué hacer y la segunda, cuando "estábamos preparados para enfrentar por clase virtual y atender a nuestros estudiantes". Esto requirió de una nueva deconstrucción del trabajo que hacíamos y tuvimos que modificarnos para un nuevo escenario. (Profesora B)
La situación específica de la Universidad Pedagógica Nacional - Ajusco antes del virus fue muy particular, el personal administrativo estuvo en huelga [...] esta situación afectó tanto a estudiantes como el semestre. Al finalizar la huelga inmediatamente, a mediados de marzo, se implementó el confinamiento [...] sí, estaba informada, estuve revisando en esta etapa estadísticas e información sobre el avance del virus, incluso fue casi compulsivo, de revisar diariamente lo que estaba sucediendo y los reportes de investigación, por lo que estaba consciente de la situación nacional y mundial. (Profesora A).

Para Martínez Bonafé (1998), el trabajo de enseñanza es una actividad laboral que requiere, para su desarrollo, de una energía vital a la que se le han incorporado conocimientos y destrezas específicos. Para que la mercancía fuerza de trabajo pueda realizar su valor — cambiarse por su equivalente en dinero-, es preciso que tenga valor de uso para que el capital que la quiere, es decir, que pueda consumirse productivamente en un trabajo concreto o cualificado:

enseñar es otra cosa de las muchas actividades laborales que requieren para su realización de alguna forma de cualificación que debe añadirse a la energía vital humana. Digamos que la educación es una necesidad humana cuya posibilidad de satisfacción descansa en parte del trabajo cualificado que ejerce el docente. (Martínez Bonafé, 1998, p. 21)

La actividad de enseñanza es considerada como parte de la energía vital, que debe añadirse a la fuerza de trabajo para que esta pueda potenciar su actividad concreta. Consideramos que la educación es un elemento constante dentro de la humanidad, necesaria para su desarrollo y es parte de la esencia misma de mujeres y hombres, como indica Freire (2002).

Conscientes a partir de las discusiones del Cuerpo de que no podíamos reproducir el proceso de enseñanza-aprendizaje llevado a cabo de manera presencial, y que teníamos que resignificar nuevamente el trabajo docente a la luz de la nueva situación, porque las condiciones materiales para dar clases se habían modificado, y que esto transformó la relación socioeducativa del proceso de enseñanza y con ello la relación humana. (Cuerpo académico Autonomía Universitaria y Educativa)

La potencialidad del trabajo docente se incrementa a partir de la organización de su trabajo, como señalan Oliveira et al.:

la organización de este trabajo se refiere a la manera como las actividades y el tiempo están divididos, a la redistribución de las tareas y competencias, las 
relaciones de jerarquía que reflejan relaciones de poder, entre otras características inherentes al modo en que el trabajo está organizado. (2004, p. 185)

\section{Trabajo y práctica docente: una labor complicada, pero resignificante}

Los integrantes del cuerpo académico, luego de horas de discusión y reflexión, decidimos que teníamos que modificar nuestras tareas sustantivas (docencia, investigación y difusión) a partir de la nueva crisis económica y social que se generó por el virus. La discusión giró en torno a qué debíamos hacer para realizar las funciones sustantivas dentro de nuestro trabajo, pero con un contenido nuevo. Iniciamos la discusión recuperando nuestra experiencia en los diferentes ámbitos y desde ahí nos planteamos las siguientes preguntas: ¿Cómo organizarnos y repensar nuestro trabajo? ¿De qué forma incorporar nuestro objeto de estudio como equipo a las tareas sustantivas que deberíamos de desarrollar como profesores? ¿Qué deberíamos hacer para que los estudiantes realmente fueran profesionales críticos y autónomos? ¿Cómo incorporar las Tecnologías de la Información y Comunicación dentro del proceso de enseñanza- aprendizaje y que esto contribuyera no solo a la resolución de los problemas socioeducativos, sino sobre todo a formar estudiantes autónomos? A partir de estas preguntas, iniciamos la nueva etapa de nuestra indagación.

El contexto social nos sumergió en una realidad que estaba trastocando todos los ámbitos, particularmente el de nuestro trabajo y la organización de este. Por ello, nuestro punto de partida fue la discusión acerca de las condiciones económicas, sociales y políticas que se generaron a partir de la crisis mundial ocasionada por la pandemia. Consideramos que esta coyuntura es parte de la crisis mundial en la que la burguesía ha sumido al mundo desde hace décadas. Sin embargo, como señala Byung-Chul (2016), cada época presenta "sus enfermedades emblemáticas", y aunque en este siglo XxI parecía que las bacterias y los virus se habían superado por las técnicas inmunológicas, este año nos sorprendió con una pandemia mundial viral. Los procesos especializados surgidos por la cuarta revolución científico-tecnológica han sido insuficientes para generar una vacuna que contribuya a minar al virus, como se plantea a continuación:

Debemos discutir el sentido de la "nueva normalidad" en el contexto del desarrollo del capitalismo, ubicarnos en la situación real que estamos viviendo
[...] Es el inicio de un proceso en una nueva etapa. El proceso inició desde hace más o menos 10 años, vivimos en una economía de guerra, en un nuevo colonialismo en una guerra comercial entre China y Estados Unidos de América., que se expresa en la carrera de las grandes empresas transnacionales por la vacuna contra el virus. (Profesor E)

La solución de paralizar y aislar a la población al inicio de la pandemia afectó de manera inmediata nuestro ámbito, el educativo. Nuestras condiciones de trabajo se transformaron, el espacio de la universidad se trasladó a nuestro hogar, del ámbito público (social) pasamos al ámbito privado (individual), al uso de nuestros recursos, computadoras personales, internet, plataformas y software diversos para continuar con nuestro trabajo.

En este sentido, la práctica educativa tenía que ser producto de un proceso social y socioeducativo en el que el educador y educando aprendieran y enseñaran juntos, en el cual ambos pudieran visualizar e identificar los obstáculos para llevar a cabo una transformación de esa realidad. La esperanza tiene que significar la búsqueda de ese cambio considerando los elementos emocionales, la experiencia histórica de estos sujetos y su problematización.

Con base en la relación dialógica entre docentes y alumnos, surgieron dudas y preguntas a partir de la curiosidad y de la sistematicidad epistemológica referida a esta problematización, en la que la experiencia del docente es discutida y es planteada; en dicha relación, podemos comprobar la respuesta a esas dudas y preguntas, en las que nos volvemos capaces de intervenir en la realidad y en la que podemos generar nuevos saberes y nuevas preguntas; finalmente es una realidad inacabada que se va construyendo de manera conjunta con los alumnos. De esto damos cuenta en la siguiente narrativa:

Al escucharnos nuevamente, teníamos que considerar que esta pandemia y la llamada "Nueva normalidad" estaban teniendo serias repercusiones en la educación, y de manera particular en el trabajo y la práctica educativa que llevamos a cabo. Un punto de partida muy importante es que todos considerábamos que el proceso educativo es un proceso humano, ubicado en un contexto histórico específico, que debe tener en cuenta la condición particular de los alumnos y los docentes, que debe respetar la situación de los actores que participan en el proceso de enseñanza-aprendizaje, en donde se debe reconsiderar tanto su autonomía como la capacidad de generar nuevas alternativas de manera conjunta. (Cuerpo académico Autonomía Universitaria y Educativa) 
La práctica docente crítica necesariamente debe reflexionar a partir de un proceso dialéctico entre el hacer y pensar sobre el hacer, esto es, saber identificar tanto el contexto histórico en el que se desarrolla el proceso de enseñanza-aprendizaje y por ende la educación, así como el contexto específico en el que se lleva a cabo esa práctica docente, la reflexión necesariamente, debe considerar, la epistemología que se pretende desarrollar en cada materia, este proceso lleva a identificar una serie de elementos en el tiempo y el espacio educativo que permiten cambiar lo que hacen los sujetos en esa realidad descubierta. (Profesora A)

[...] debemos pensar en clases para sostener la vida, porque el desempleo, la falta de comida, la escuela vacía, ya no juega el papel de la socialización. Debemos abrir espacios para la vida, buscar un sistema educativo para la vida, que dé respuestas para sostener la vida misma. (Profesor c)

Esta realidad descubierta, de experiencia histórica, política, cultural, social y educativa, se revela dentro del inacabamiento del ser humano, por ende el sujeto tiene la posibilidad de transformar esta realidad. El docente tiene que verse como este sujeto histórico, vinculado y relacionado con los otros, verse en ellos mismos, identificarse con ellos en lo emocional y ético, lo que le permite a través del lenguaje, de la cultura, de la comunicación, promover cambios que signifiquen para quienes intervienen en el proceso socioeducativo nuevas representaciones que den un sentido distinto a esa realidad y contexto, que den un sentido de esperanza.

La práctica docente que se sabe como de inacabamiento del ser humano es lo que nos da la posibilidad de desarrollar la autonomía en el educando a través del respeto de su conocimiento socialmente construido, de la experiencia desarrollada a través de un proceso dialógico a través del cual se aprende el respeto y el inacabamiento de cada uno. Gracias a la relación entre el docente y el alumno, es posible actuar de manera ética y transformar los saberes de estos seres humanos. Es un proceso de concientización en el que se debe respetar a los educandos, su dignidad, su ser en formación, su identidad en construcción... (Freire, 2002).

Esta nueva relación socioeducativa responde al contexto actual, pero se tiene latente en que esta modalidad de enseñanza virtual no será la definitiva, se tiene que regresar a las aulas, porque es la forma en cómo se dan las relaciones sociales y se construyen a sujetos más críticos y empáticos con su entorno. (Profesor c)
La labor educativa como profesores se transformó desde lo que Freire planteó como una posición ética, de compromiso, en donde, el profesor construye nuevos saberes tales como: la seguridad, el compromiso, la comprensión, el saber escuchar a los alumnos, la empatía y flexibilidad en un contexto de miedo. (Profesora A)

Entonces se trata de asumir una posición reflexiva del entorno actual, que evolucionará al paso del tiempo. Poner al sujeto por delante, se trata de educar para la formación de la persona, no para el beneplácito del sistema mismo. Se trata de encontrar a la persona situada en un mundo y una realidad. Como primer paso enfrentar a la pandemia, que es enfrentar al mundo, que es educar en y para la pandemia, que es educar para la vida, que es como reza nuestro lema en la Universidad Pedagógica Nacional, educar para transformar.

nos trasformamos desde la auto reflexión de la práctica docente, las formas de enseñanza en diversos escenarios, pero, sobre todo, en lo emocional, ya que enseñar implica más que adiestrar o informar, es un compromiso que se tiene con el estudiante y por qué no, con la misma sociedad. (Cuerpo académico)

Como hemos sostenido, la primera función sustantiva para repensar fue la docencia. Para ello, planteamos una construcción nueva en las relaciones sociales y el uso de la autonomía como detonante para aprender a enfrentar esta situación, aprender a ser feliz, a vivir feliz, a no solo enseñar, sino también a aprender a investigar, a enseñar a vivir, replantear la lógica y la discusión a la luz del nuevo contexto. Por ello, decidimos discutir y elaborar nuevos conceptos que nos brindaran la posibilidad de dar cuenta de la realidad que estábamos viviendo. La pandemia nos enfrentó a nuevas formas de trabajo que resignificaron, nos cambiaron y modificaron el espacio y el tiempo en el que desarrollábamos dicha actividad. Nuestra vida en la casa con la familia, considerada como un espacio privado se transformó en un escenario público. El espacio en donde se realizaba el proceso de enseñanza-aprendizaje con relativa autonomía se modificó y por ende la relación socioeducativa cambió. Esto lo visualizamos y lo planteamos en el siguiente relato:

El aislamiento social obligatorio demandó modificar las anteriores rutinas de aprendizajes, en donde la separación entre lo académico y lo privado era claro. En estos momentos en cada instante queda trasgredida la esfera de lo privado tanto en la vida del estudiante como del docente. Por ello, cabe fortalecer el diálogo entre pares por docente y estudiante para humanizar la condición de ambos ante este embate de su privacidad. (Profesor D) 
Como colectivo, decidimos reconocernos como sujetos, como seres humanos con las mismas condiciones; la diferencia era nuestra formación profesional y nuestra experiencia. Nuevamente la crisis del sistema capitalista nos obligó a tomar una postura ante la vida, pero no de manera individual. Por ello, decidimos actuar de forma colectiva, resolvimos tomar como punto de referencia la autonomía y relacionar este concepto con lo señalado por Freire sobre el proceso de enseñanza-aprendizaje, esto es, relacionar teoría-práctica, actuar en función de la práctica docente crítica.

\section{El uso de las tecnologías en un nuevo contexto}

La tendencia de la incorporación de las Tecnologías de la Información y Comunicación a la educación no es un factor nuevo; su uso no solo se circunscribe a la generación o producción del conocimiento, sino sobre todo a su mercantilización. La generación de redes y la mundialización han llevado hacia la comercialización de los servicios educativos en este nivel. Las expresiones "educación sin fronteras", "educación transnacional", "educación a través de las fronteras" o "educación transfronteriza" son las conceptualizaciones utilizadas para definir las políticas educativas en este nivel, directrices que se orientan no solo a la privatización de la educación sino también a la profundización de la desigualdad a su interior y a la modificación del proceso de enseñanza-aprendizaje y por ende a la transformación del trabajo docente. En consecuencia, los profesores deben aprender la lógica digitalizada, en donde la información se almacena y recupera con velocidad y rapidez; el reto que se enfrenta es transformar tal información en conocimiento. La coyuntura del SARS - CoV- 2 virus aceleró un proceso que inició en la década de los setenta del siglo anterior con la instauración del proceso de globalización.

Esta situación ha modificado considerablemente el trabajo del docente en la educación superior, quien ha tenido que incorporar nuevas formas y estrategias conforme a esta coyuntura. No se trata solo de la necesidad de añadir dentro del proceso de enseñanza-aprendizaje algunas herramientas tecnológicas digitales, tales como el uso de internet, las exposiciones en PowerPoint o Prezi, las discusiones en los blogs o el empleo de software, sino de utilizar estas herramientas para que los alumnos puedan analizar problemas y sean capaces de crear nuevas alternativas ante los cada vez más complejos problemas de la educación. Al igual que en el mundo productivo, las habilidades, las destrezas y los conocimientos de los docentes tienen que transformarse de manera permanente y a la misma velocidad que las fuerzas productivas.

Se exige a los profesores que cumplan y se transformen acorde a los requerimientos del mercado dado que son ellos los que están formando a los nuevos profesionales. El reto entonces para nosotros como equipo de trabajo académico era considerar este entorno y cumplir con las funciones sustantivas de la universidad, pero de una forma crítica.

Analizamos el entorno y creímos importante y necesario buscar la forma para que los alumnos utilizaran esta tecnología no solo para obtener información sino para incorporarla y de esta manera resolver problemas. Esto con el fin de formar estudiantes críticos y conscientes de su realidad social, que pudieran examinar su contexto, mirar y analizar más allá de la mera reproducción del esquema capitalista, si no en un sentido crítico y propositivo.

\begin{abstract}
las continuas revoluciones científico-tecnológicas nos han llevado a crear nuevos conceptos, en la 4 ta y 5 ta revolución se habla de "nómadas del conocimiento", en éstas, la robótica, el uso de la física y matemáticas para crear algoritmos como la "data" la inteligencia artificial entre otros, nos obliga a buscar nuevos conceptos. Hoy que tenemos ¿clases virtuales? o ¿clases en línea? ¿qué pasa con la relación interpersonal? ¿qué pasa con el contacto presencial y la socialización y esto como se modifica? ¿educación pública virtual o en línea? ¿Qué hacer frente a ello, como conceptos de una educación liberadora nos ayudan? (Profesora A)
\end{abstract}

No podemos considerar que toda la tecnología es dañina para el proceso de enseñanza - aprendizaje; al contrario, su uso potencia el desarrollo cognitivo de los sujetos. Sin embargo, creemos que el problema es que un porcentaje alto de la población no tiene acceso a estas tecnologías, lo que ocasiona que se amplié la brecha digital.

En esta coyuntura consideramos que debe abordarse la desigualdad generada en la educación por el uso de las Tecnologías de la Información y Comunicación y buscar disminuir esa brecha en los alumnos de la Licenciatura en Sociología de la Educación. Consideramos que una de las formas con las que se puede avanzar en la transformación de tal desigualdad es fomentar la autonomía propiciando en los alumnos la libertad para que ellos desarrollen y planteen problemas dentro del ámbito de su formación y sean capaces de identificar los instrumentos que les puedan ayudar a resolverlos. Otra forma es promover la colaboración en equipo: no se trata solo de formarlos en competencias específicas 
según los requerimientos empresariales como futura fuerza de trabajo capacitada o útiles mercancías, sino de enseñarles la importancia del trabajo colegiado, no en términos de los círculos de calidad, sino en cuanto a la colaboración y el respeto a la opinión y el trabajo de los demás. Es esencial también fomentar la discusión y la investigación de problemas socioeducativos. El uso de las tecnologías es un instrumento de formación alternativa, siempre y cuando exista un uso crítico de ellas y propicien un entorno reflexivo, que coadyuve a que el docente que por un lado, transmita conocimientos y contenidos de formación, y por el otro, trabaje experiencias socioemocionales con los estudiantes, esenciales en la construcción de un sujeto consiente de su entorno, empático y responsable de la sociedad que le tocó vivir.

\section{Algunas conclusiones}

El trabajo y la práctica docente de los profesores de educación superior en el contexto de la pandemia exigieron una transformación significativa de su quehacer académico y cotidiano. Se incorporaron nuevas formas y estrategias didácticas en el proceso de enseñanza-aprendizaje, lo que aceleró el proceso de nuestra incorporación a la era de la digitalización. Adaptamos las funciones sustantivas que debemos cumplir (docencia, investigación y difusión) en tiempos y espacios distintos, lo que nos obligó a revisar nuestro quehacer y trabajo académico.

Como país, empezamos a vivir un contexto de ambigüedad y como profesores, en la universidad, un nuevo proceso de relación socioeducativa entre los actores que se construyen en la cotidianidad universitaria, la cual fue mediada por las nuevas tecnologías, a través de los instrumentos digitales. Se inició con el establecimiento de nuevas formas, normas, patrones etc. de relación socioeducativa, lo que nos llevó a reconfigurar nuestros saberes y procesos de formación. La nueva condición nos ubicó a los docentes y a los alumnos en la misma situación, es decir, ambos teníamos que aprender del contexto que enfrentábamos por el virus, del contagio, de sus efectos, etc. Por primera vez, consideramos la educación como una práctica en donde el proceso de enseñanza-aprendizaje tenía que ser dialógico en una misma situación, en la que tanto docentes como alumnos aprendíamos y enseñábamos, no solo de la pandemia, sino de sus implicaciones económicas, sociales y por supuesto educativas.

Históricamente, los movimientos sociales y educativos nos habían mostrado muchos elementos para aprender, pero esta coyuntura por el virus nos permitió vernos como seres humanos, identificarnos el uno con el otro. A través de esta relación, consideramos que debía transformarse la reproducción de la educación bancaria, sus reglas, normas y determinaciones, los viejos programas de las materias, las investigaciones sobre otras temáticas y el papel que como docentes debíamos desempeñar, ya que determinamos que eran pautas que se presentaban como una limitante para la docencia, y surgió en las clases la empatía, la solidaridad, la comunicación colectiva e interpersonal, el respeto, etc., como elementos de convivencia establecidos por ambos actores del proceso educativo, ante este virus.

Como producto de la reflexión y del análisis de las narrativas, propusimos la autonomía y la libertad como eje del proceso educativo, y estos se convirtieron en los elementos centrales. El implementarlos como una alternativa para esta coyuntura en la docencia nos permitió establecer una relación dialógica con los alumnos, utilizar diversas plataformas acordes a las condiciones digitales de los alumnos, una mayor flexibilidad en el uso de las herramientas e incorporar paulatinamente las alternativas que los alumnos iban planteando para resolver los problemas surgidos por la crisis social y económica que generó la pandemia.

En este contexto, la necesidad de transformar y resignificar nuestra labor y práctica docente nos llevó, en primer lugar, a organizar las actividades de docencia a partir del rompimiento de esquemas y reglas reproducidas continuamente, a reformular el formato del programa de las materias, a elegir lecturas de libros digitales, y a modificar las formas de evaluación y, sobre todo, las estrategias y didácticas implementadas.

Uno de los elementos más significativos que como grupo académico construimos fue la forma de organizar el trabajo colectivo del cuerpo académico Autonomía Universitaria y Educativa al elaborar una estructura de enseñanza-aprendizaje a través de la experiencia y la práctica de los estudiantes, recuperando desde la reflexión, tanto de los alumnos como de nosotros, a través de narrativas, nuevas formas de trabajo académico en donde confluyeron los saberes en función de las experiencias y los conocimientos construidos, lo cual se vislumbró desde las narrativas obtenidas.

En el área de la investigación sobre temáticas específicas de la crisis de la pandemia y sus repercusiones en la educación superior, el cuerpo académico construyó nuevas formas teóricas- conceptuales, así como metodológicas para la conformación de un conocimiento significativo en una era digital en donde es necesario recuperar las voces de los seres 
humanos en una función más colectiva y significativa de los sujetos que reconstruyen su sentir a partir de la subjetividad.

Como sociólogos de la educación, podemos señalar de manera específica que la pandemia permitió que nos incorporáramos a la era digital por completo: se generalizó el uso de plataformas, información, redes, que con frecuencia se utilizaban en la educación de manera individual, y esto permitió que la educación se reorganizara a partir de lo virtual.

Producto de la reflexión en el Cuerpo Académico llegamos a la conclusión de que existían posibles soluciones para impulsar una educación con otro carácter. La primera, reorganizar y resignificar la educación y nuestro trabajo como docentes en sentidos democrático y humano, así como impulsar un proceso de enseñanza-aprendizaje con autonomía y libertad en el que nos formáramos con características de tipo crítico y de compromiso social, en el que el ambiente digital y las herramientas tecnológicas las utilicemos para avanzar en construir una sociedad democrática. Cabe mencionar que esto, nos exigió subirnos al tren de la tecnología e impulsar una educación virtual que utilizará las herramientas tecnológicas y el conocimiento para innovar dentro del mundo de la competencia y el mercado y dar continuidad al cambio de paradigma técnico-económico impulsado por el modelo neoliberal.

Por lo anterior, consideramos que este proceso se resume en:

- La resignificación del trabajo docente en un contexto complejo o de crisis.

- La desestructuración de las formas de enseñanza-aprendizaje tradicional hacia una donde el uso de las herramientas digitales son lo principal.

- La transformación e implementación de nuevas didácticas digitales en las clases en línea.

- La modificación conceptual del proceso de enseñanza-aprendizaje. Nuevos constructos de aprendizaje a partir de la relación dialógica entre el profesor y el alumno.

- El contexto de la pandemia en una nueva concepción de la educación.

- Los contextos económicos, políticos, sociales, culturales y de salud que deconstruyeron a los profesores y a los estudiantes.

- Las nuevas formas de relacionarse a nivel socioemocial y afectivo desde las herramientas digitales.
- El reconocimiento del yo y del otro en una posición igual frente a la pandemia.

Finalmente, establecemos que la discusión nos llevó por nuevos caminos: no solo fue retomar la educación como instrumento liberalizador, sino como elemento de construcción de la autonomía de nosotros como docentes y de los alumnos. A partir de la reflexión, consideramos que la situación mundial y en particular de México cada vez estaba más complicada. Sin embargo, observamos que los puntos en confluencia tenían que ver con la resignificación de nuestro trabajo en la docencia vinculado estrechamente a la autonomía y a la búsqueda de nuevas formas de organización de nuestro trabajo y de nuestra labor diaria, así como la lucha por una educación democrática.

\section{Referencias}

Bolívar, A. (2002). ¿De nobis ipsis silemus?: Epistemología de la investigación biográfico-narrativa en educación. Revista Electrónica de Investigación Educativa, 4(1). http://redie.uabc.mx/index.php/redie/article/ view/49

Bloch, E. (1985). El método dialéctico. En Sujeto-Objeto. El pensamiento de Hegel (pp. 116-142). Fondo de Cultura Económica.

Byung-Chul, H. (2016). La sociedad del cansancio. Herder.

Castillo, M. (2019). Reconfiguración de la organización del trabajo de los docentes de secundaria general en el aula y la escuela, en la Ciudad de México 2006-2016. [Tesis de doctorado, Universidad Nacional Autónoma de México].

Ferrarotti, F. (2011). Las historias de vida como método. Acta Sociológica, (56), 95-119.

Freire, P. (2002). Pedagogía de la autonomía. Saberes necesarios para la práctica educativa. Siglo XXI. Editores.

Freire, P. (2011). Política y educación. Siglo xxi Editores.

Freire, P. (1998). Pedagogía del oprimido. Siglo XXI Editores.

Imaz, C. (2011). Descongelando al sujeto. Subjetividad, narrativa e interacciones sociales contextualizadas. Acta Sociológica, (56), 37-57.

Martínez Bonafé, J. (1998). Trabajar en la escuela. Profesorado y reformas en el umbral del siglo Veintiuno. Instituto Latinoamericano de la Comunicación Educativa.

Oliveira, D., Goncalves, G. y Melo, S. (2004). Cambios en la organización del trabajo docente. Investigación Temática, Trabajo Docente y Subjetividad Magisterial, 9(20), 183-197. 
Velasco, A. (2012). Hermenéutica y ciencias sociales. En E. de la Garza y G. Gustavo (coords), Tratado de metodología de las ciencias sociales: perspectivas actuales, (pp. 134-198). Fondo de Cultura Económica - Universidad Autónoma Metropolitana. 
